Session ????

\title{
Increasing Georgia's Hispanic Community into Higher Education
}

\author{
Barbara Bernal Thomas \\ School of Computing and Software Engineering \\ Southern Polytechnic State University \\ Marietta, Georgia 30060 \\ bthomas@spsu.edu
}

\begin{abstract}
A comprehensive study of Georgia's Hispanic population will enable academia to understand the historical progression of the Hispanic population in the state. The implications of this progression can help us address the overall impact of this population in academia. We want to ensure access to educational opportunities for the Hispanics. Other states can use this study to understand what the issues in Georgia are, gain knowledge and compare their state's situation with regard to this growing community.
\end{abstract}

\section{Introduction}

The terms "Hispanic" and "Latino" are complex and include a range of cultures, races, ethnicities, nationalities, and even languages. The Hispanic population in the United States originates from countries primarily in Central America, South America and the Caribbean. These include Mexico, Costa Rica, El Salvador, Belize, Honduras, Nicaragua, Cuba, Puerto Rico, Dominican Republic, Guyana, Argentina, Brazil, Colombia, Peru, and also Spain and Portugal. ${ }^{3}$

Georgia has noticed an explosive growth in the state's Hispanic population, currently at 475,000 and projected to increase to more than one million by 2020. Two decades has yielded an increase from 1 percent of Hispanics in metro Atlanta to the current 7 percent. The average age of Hispanics in Georgia in 1999 was 26.4 years old. The U.S. Census predicts the average age will be 28.1 in the year 2015. Nationally, the Hispanic population is younger than other populations; for example, under 15 years of age,

- Hispanic $30 \%$,

- African American 21\%,

- White non-Hispanic $20 \%{ }^{3}$

What are the implications? We could suggest given this heavily younger population there is a definite opportunity to impact them while they are concentrated with in the K-12 education. This outreach can translate to opportunities for further higher education for Hispanics. 
Indisputably, improvements in the extent and quality of education will raise the economic prospects, well-being, and civic engagement of the Hispanic population. Hispanics are now the most poorly educated major population group in the United States.

- White males average 13.3 years of schooling and

- African American males average 12.2.

- Hispanic males lag behind with 10.6 years of schooling.

Hispanics are more likely to be unemployed, to earn less, and to live below the poverty line. ${ }^{3}$ Some of this achievement gap reflects low levels of education among many Hispanic immigrants but that is by no means the entire problem. The U.S. born Hispanic males average only 12.0 years of schooling. ${ }^{4}$ Why do the immigrating Hispanic and the U.S. born Hispanic hesitate beyond a high school degree? One possible answer may be the Hispanic belief which assumes financial family support from their children once they are sixteen. A common response to a Hispanic declining scholarships for higher education is the lost of income that Hispanic brings to the family budget.

Hispanic students drop out of the "educational pipeline" at a relatively high rate, both nationally and in Georgia. Currently, those who do enroll in Georgia's University System are as likely to persist and graduate as students from any other population. The primary barriers to accessing the available higher education systems are languages issues and academic preparation, finances (especially related to the family budget), and residence issues. The major challenge to the state of Georgia is to find ways to encourage Hispanic students to persist in high school through graduation and to ensure they are financially able and academically prepared to enroll in a college or university. The study and analysis for solutions must encompasses the entire family profile of the Hispanic not the single individual seeking higher education.

The fact that $78 \%$ of Hispanics speak Spanish in the home can enrich the educational community. ${ }^{1}$ This bilingual and bicultural capability has positive effects on learning. It shows a greater ability to comprehend abstract aspects of language and as a result demonstrate greater cognitive flexibility. A campaign to bring Hispanics into higher education because of the added value they bring forth can motivate the Hispanic family to support their children's educational achievements. The fact that "life-time earnings are closely tied to education achievement" ${ }^{2}$ makes education advancement critical to the economic success of the entire Hispanic family.

\section{Hispanic Growth in Georgia}

The state of Georgia has witnessed phenomenal growth among the Hispanic population in the last decade. Currently, 2000 Census figures show that there are almost 475,000 Hispanics in Georgia, an increase of 300 percent since 1990. Additionally, Georgia was the 4th most popular state for newly arrived Hispanics in the 1990s. As the Hispanic population grows at such overwhelming rates, it is becoming increasingly harder to ignore the escalating economic, social, and political presence Hispanics now have in the state of Georgia.

Metro Atlanta has also experienced one of the most significant demographic changes in the state, currently home to more than 50 percent of the state's total Hispanic population. In 1980 the 24,550 Hispanics represented 1 percent of the metro population. After 20 years, Atlanta's 
Hispanic population reached 268,851 which represents' 7 percent of the total population in Atlanta. This is a 995 percent growth rate. The Center on Urban \& Metropolitan Policy and The Pew Hispanic Center labels Atlanta a "Hypergrowth" New Hispanic Destination.5 At present, Atlanta ranks 31 in the list of top 50 metropolitan areas for Hispanics.

\section{Statistics of Hispanics in Higher Education}

Statistics are gathered regarding educational levels between the Hispanic immigrant population into the United States and that of the U. S. born population. These statistics point towards a significant improvement made for the Hispanics during the past three decades. These gains have not produced a notable convergence with the level of education in the native-born U. S. population due in part to marked improvements of education in U. S. that outpaced the progress of the immigrant's. The number of high school educated Hispanic immigrants has doubled, and the number with less than high school has decrease by one-half. ${ }^{1}$ These changes produced an improved educational profile of the entire adult Hispanic immigrant po pulation.

Statistics regarding Hispanics that attend schools in the U.S. have also improved. More than 80 percent complete high school or college; that figure is approximately 10 percent points less than the average of the entire United States population. Nearly 25 percent of American-educated Hispanic immigrants complete an associate's college degree or better. This improvement is due to schooling is more universal in America, and foreign-born Hispanics who arrive as children usually complete more years of education than those who arrive as adults. Currently a greater share of Hispanics are immigrating in childhood and completing their education in the U. S. ${ }^{2}$

During the 1990's Hispanic completing two-year degrees was such a marked increase that now they are higher to the white population in the U. S. It may be that the associate's degree completion is seen by the Hispanic family as a short commitment to obtain an increase in life-time earnings for them. This may also be "the first phase of an inter-generational increase in education"'. Increased Hispanic parents with high school education yield the next generation with two-year community college education.

\section{Conclusions}

This paper presented a study of Georgia's Hispanic population and the implications of the numbers found in the study. Important statistics regarding Hispanics' gains in their native educational systems before arriving and the internal educational gains in the U. S. where introduced and discussed.

Hispanic immigrants supply a significant and growing share of the workers in the United States. Education remains critical to the economic success of the Hispanics for the simple reason that lifetime earnings are closely tied to educational achievement. Substantial benefits can be reaped from programs that aim to bolster the education of Hispanic youths and to provide adults with language and skills training. Educational achievement is - and will continue to be-a critical factor in determining whether or not millions of foreign-born and U.S. born Hispanics will more forward. 


\section{Bibliographic Information}

1. Fry, R. "Latinos In Higher Education: Many Enroll, Too Few Graduate", Pew Hispanic Center (September 5, 2002) http://www.pewhispanic.org/site/docs/pdf/latinosinhighereducation-sept5-02.pdf

2. Lowell, B. L., Suro, R. "The Improving Educational Profile Of Latino Immigrants", The Pew Hispanic Center (December 4, 2002) http://www.pewhispanic.org/site/docs/pdf/ImmigEd12-04-02Final2.pdf

3. Report of the Hispanic Task Force of the Board of Regents University System of Georgia (June 1999)

4. Smith, J. P., "Race and Ethnicity in the Labor Market: Trends Over the Short and Long Term," in America Becoming: Racial Trends and Their Consequences. Washington, DC: National Academy Press. (2001)

5. Suro, R., Singer, A. "Latino Growth In Metropolitan America: Changing Patterns, New Locations", Pew Hispanic Center and Brookings Institution Center on Urban and Metropolitan Policy (July 2002)

\section{Biographical Information}

\section{BARBARA BERNAL THOMAS}

Thomas is a full professor in the School of Computing and Software Engineering at Southern Polytechnic State University for the last seventeen years. The areas of Software Engineering, User-Centered Design and Computer Graphics \& Multimedia are the focus endeavors. She is a co-founder of the SPSU Usability Research Lab and is directly involved in corporate-sponsor ULAB projects. 